\title{
ELECTROLESS PLATING - ITS APPLICATIONS IN RESISTOR TECHNOLOGY
}

\author{
J. DEARDEN \\ Welwyn Electric Ltd., Bedlington, Northumberland, U.K. \\ (Received January 8, 1976; in final form May 12, 1976)
}

\begin{abstract}
Electroless processes for the deposition of metal films onto insulators have been known for many years. Various aspects of this technology have been applied in the field of resistor technology leading to improved performance of existing resistors and the evaluation of new resistors with novel characteristics.

The applications of electroless nickel as a readily solderable, completely ohmic contact for tin oxide resistors is described.

Copper oxide layers produced from oxidised electroless copper are shown to improve the thermal stability of tin oxide resistors.

A range of electroless high precision metal film resistors from a fraction of an ohm to $100 \mathrm{kohm}$ per square and from a few millimetres in length to over 1 metre is shown to be feasible. This technology has been applied to the manufacture of thin film circuits.

The outstanding thermal stability of the electroless nickel-boron films and their temperature coefficient of resistance indicates a potential application in the field of temperature sensors.

The ability to produce "weightless" films on Mylar sheet at $10 \mathrm{Gohm}$ per square is considered to be a solution to the charge distribution requirement for electrostatic loudspeakers.
\end{abstract}

\section{INTRODUCTION}

With the rapid growth in the knowledge of electroless plating techniques over the past 30 years it was inevitable that it should attract the attention of technologists working with thin film electronic components.

One of its main attractions was the fact that metal films could be deposited onto non-conductors under low temperature conditions and in very mild solution ambients. In addition the outlay on equipment to deposit these films constituted no more than the cost of simple everyday laboratory items.

This paper summarises some of the pertinent literature and describes some of the uses of electroless plating in resistor technology, indicating why it was contemplated at the particular time and in some cases how it gave a successful answer to the problem.

\section{LITERATURE SUMMARY}

The electroless deposition of metals is usually carried out by reduction in an aqueous solution of a metal salt either by an organic or an inorganic reducing agent dissolved in the solution. The reduction process requires the presence of catalytic nuclei before it can take place effectively.
Silver was the first metal to be deposited in film form, to replace the rather dangerous silver-mercury amalgam previously used in the manufacture of mirrors. In 1826 Von Liebig found that by heating acetaldehyde with an ammoniacal solution of silver nitrate in a glass vessel a brilliant silver mirror formed on the surface of the glass.

A search of the technical and patent literature on silvering processes discloses a vast number of papers on the subject in a wide variety of languages. Most of the quoted processes involved the pre-treatment of the surface to be silvered with a dilute solution of stannous chloride, which provided catalytically active centres to promote silver deposition. The plating solutions used are numerous and a selection of these can be found in a summary article by Wein. ${ }^{\circ}$

Like silver, copper films can be deposited onto non-conductors by a similar chemical route. However, in order to promote the deposition it is usually necessary to have a trace of a precious metal salt in the metallising solution. In another article Wein ${ }^{2}$ describes some of the more successful electroless copper solutions.

The deposition of nickel and its alloys has attracted much attention during the past thirty years due mainly to the chemical inertness of the films and their interesting electrical and magnetic properties.

As with silver and copper, the films are formed by 
reduction of solutions of nickel salts. A nickelphosphorus "alloy" can be deposited using sodium hypophosphite as the reducing agent. The reaction was first observed by Wurtz ${ }^{3}$ in 1844 ; it was, however, a spontaneous uncontrolled reaction which produced only a black powder.

It was not until 1947 that Brenner and Ridde $11^{4}$ at the American National Bureau of Standards demonstrated that a stable and controllable plating process was possible onto certain chemically active metallic surfaces. They also showed that once the reaction had been started it was autocatalytic thus allowing thick deposits to be formed, a feature which was absent in the silver and copper reactions, both of these processes being self limiting.

Depositions onto non-metallic surfaces did not meet with much success until Brenner ${ }^{5}$ reported on a method of sensitising insulating surfaces by rinsing in stannous chloride solution followed by a rinse in a dilute palladium chloride solution. This deposited a monoatomic layer of a palladium-tin complex on the insulating surface which in turn was highly catalytic towards the hypophosphite reduction of the nickel solution.

Gutzeit ${ }^{6}$ showed that the phosphorus content of these films could be varied between 7 and 15 per cent by changing the $\mathrm{pH}$ of the plating solution.

Because of the brittle nature of the nickel phosphorus film several attempts were made to find alternative reducing agents. Dini and Coronado ${ }^{7}$ were successful in producing almost pure nickel films by using hydrazine instead of sodium hypophosphite. After suitable heat treatment these deposits were shown to be highly ductile and possess interesting magnetic properties i.e. low coercivity, high saturation magnetisation and hysteresis loops with high squareness ratios.

Other classes of reductants for electroless nickel plating which have received a considerable amount of attention are the borohydrides and boranes. These produce nickel films with up to 7 per cent boron, and Narcus, ${ }^{8}$ in a useful summary paper, claims that these processes, because of their low temperature operation, are particularly useful for applying conductive metal films to temperature sensitive thermoplastics. He also claims that after heat treatment on refractory substrates, nickel boride is formed in the film endowing it with a high degree of abrasion resistance and chemical inertness.

It can be seen from this brief survey on a widely subscribed topic that anyone who is working in the field of thin film components could not help resorting, at some time, to its information for solutions to prob- lems or as a basis for a new component. A useful reference book by Goldie ${ }^{14}$ on the general topic of electroless deposition of metal films is now available.

\section{ELECTRICAL CONTACT CONSIDERATIONS FOR TIN OXIDE FILM RESISTORS}

Shortly after the introduction of the tin oxide film resistor a need arose to dispense with the then rather bulky turned brass caps used for the end contacts.

The obvious answer was to produce a resistor with metal film contact bands with lead wires soldered directly to the metal film. The proposed design is shown in Figure 1.

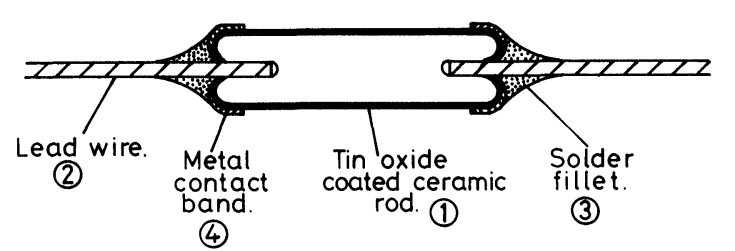

FIGURE 1 Capless Resistor Design

The tin oxide coated ceramic rod (1) had "blind" holes at each end into which the tinned copper lead wires (2) could be inserted and subsequently soldered (3) onto the metal contact bands (4) (numbers refer to Figure 1). If this type of construction could be achieved then it would eliminate the use of the costly brass caps and provide a smooth projectionless outline to the resistor.

The key to the success of this design was the provision of a satisfactory metal contact which would:

a) Give a good electrical contact to the tin oxide film

b) Have adequate adherence

c) Solder easily

Both electroless silver and copper films were tried and both gave excellent electrical contacts but soldering difficulties were encountered due to their high level of solubility in molten solder aggravated by their thinness and open pore structure.

As an alternative, "fired on" thick film silver contact bands were investigated. These gave excellent adherence and were readily soldered using solder containing a small percentage of silver. However, the electrical quality of the contact was poor due to a 
high resistivity tin oxide layer which formed at the interface between the silver and the resistive film during the firing on of the contact bands at a temperature around $500^{\circ} \mathrm{C}$.

It was clear that copper and in particular silver were not offering a solution to this particular contact problem. However, at this time the Brenner process was becoming widely known for the deposition of nickel-phosphorus films onto nonconductors.

This process seemed to have much to offer because, like the electroless silver process, the films were deposited under low temperature reducing conditions and in addition the reaction was self catalytic, thus holding out the possibility of producing thick films less likely to give soldering problems.

The usefulness of this approach was subsequently proven and it gave the required quality of electrical contact, adequate adherence, and, most important of all, problem-free soldering with no leaching of the metal contact by the solder.

A bonus which came to light during the early experiments was that the tin oxide resistive film had a sufficiently high content of lower valency tin atoms that it could itself initiate the deposition of the nickel-phosphorus film. ${ }^{9}$ This constrained the metal deposition to the exposed tin oxide end bands and no metal deposition occurred on the centre masking lacquer, thus allowing its easy removal with the appropriate solvent.

Using this electroless nickel method for applying contacts onto tin oxide resistors a successful automatic process was evolved to produce resistors according to the design shown in Figure 1. With this design the ultimate requirement for a smooth, conformal outline resistor was achieved.

\section{IMPROVING THE ELECTRICAL STABILITY OF TIN OXIDE RESISTORS}

Tin oxide resistive films by the very nature of their formation, i.e. high temperature hydrolysis of "doped" stannic chloride vapour, ${ }^{10}$ depend for their conduction on a degree of oxygen deficiency.

Under normal use these films have a high degree of electrical stability. There are certain extreme conditions, however, either during manufacture or in use, in which the resistive film can encounter mild reducing effects leading to an increase in the level of oxygen deficiency and hence a lowering of the resistivity of the tin oxide film.
To avoid such damage occurring, some thought was given to the possibility of interposing a source of oxygen between the tin-oxide and its surroundings. A wide range of chemical oxygen sources was examined ranging from chromates and peroxides to a broad spectrum of elemental oxides.

The ideal solution was ultimately discovered in cupric oxide, the optimum protection being given when this material was formed as a layer in intimate contact with the tin oxide film.

A cheap and convenient method ${ }^{11}$ of forming this cupric oxide layer was found using electroless plating techniques.

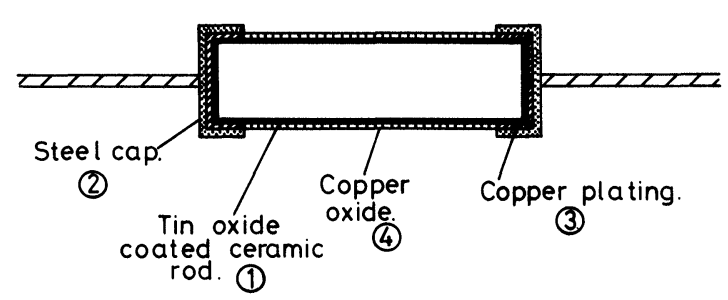

FIGURE 2 Construction of Tin Oxide Resistor with improved electrical stability

In Figure 2 the tin-oxide coated ceramic rod (1) was copper plated by one of the established electroless plating methods. After plating, steel caps (2) were pressed onto the ends of the resistor over the copper plating (3) thus ensuring perfect electrical contact to the tin oxide film. The exposed copper film between the caps was then fully oxidised (4) by heating for 3 hours at $300^{\circ} \mathrm{C}$. This caused no damage to the tin oxide film but provided a high resistivity compact oxide barrier layer.

After the formation of the copper oxide layer the resistor was brought up to value by the cutting of a helical groove through the copper oxide and tin oxide. The tinned copper lead wires were then welded onto the caps and the appropriate organic lacquer protection applied.

The presence of the copper oxide kept the processing changes to a fraction of their value before the use of this protective layer, thus enabling closer tolerance resistors to be produced.

\section{NEW COMPONENTS}

\subsection{Metal Film Resistors}

The ability to deposit metal films onto ceramic surfaces by simple and inexpensive techniques was an 
obvious invitation to examine their electrical properties.

In 1959 a comprehensive investigation programme was started to study the nickel/phosphorus and cobalt/phosphorus electroless films to see if they were capable of yielding useful resistor properties. The films were deposited by the then classical method of activating the ceramic surface by treatment with stannous chloride/palladium chloride followed by deposition of the film from a buffered nickel and/or cobalt salt solution using sodium hypophosphite as the reducing agent.

The investigations were far-reaching and covered all aspects of the process. Detailed electron microscopy studies were made of the activation stage and the early stages of film formation in order to establish the optimum conditions to achieve a high degree of film uniformity; an important requirement for resistive films.

Methods of varying the composition of the films were examined and the subsequent effect of this on the film resistivity and temperature coefficient of resistance (T.C.R.) was determined.

For any resistive film to be useful as a resistor it must be electrically stable at elevated temperatures whether these be determined by the ambient temperature or by the electrical power being dissipated by the resistor. It was necessary to establish techniques to induce this stability because, as deposited, the films were shown to be highly unstable both thermally and in moist ambient conditions.

It became evident that by varying the composition and $\mathrm{pH}$ of the electroless nickel plating bath the phosphorus content of the deposited film could be accurately controlled. This change in film composition manifested itself as a change in resistivity of the alloy and hence in the surface resistivity of the film itself. One of the interesting features was that a relatively large change in resistivity resulted in only a small change in T.C.R.

By combining this effect with a variation of film thickness it was possible to produce a range of surface resistivities from less than $1 \mathrm{ohm}$ per square to $500 \mathrm{kohm}$ per square with T.C.R.'s within $\pm 100 \mathrm{ppM} /{ }^{\circ} \mathrm{C}$.

The actual relationship between film thickness, composition and surface resistivity is shown in Figure 3. In Figure 4 the results of 400 T.C.R. measurements ${ }^{12}$ taken from production control records are plotted against their corresponding surface resistivities. They indicate a mean T.C.R. of $+4 \mathrm{ppM} /{ }^{\circ} \mathrm{C}$ with a standard deviation of $24 \mathrm{ppM} /{ }^{\circ} \mathrm{C}$.

\begin{tabular}{|c|c|c|c|}
\hline $\begin{array}{c}\text { Mean Surface } \\
\text { Resistivity } \\
\Omega / \text { Squ. }\end{array}$ & $\begin{array}{c}\text { T.C.R. } \\
\text { ppM } / \circ^{\circ} \mathrm{C}\end{array}$ & $\begin{array}{c}\% \\
\text { Pho sphorus } \\
\text { by weight. }\end{array}$ & $\begin{array}{c}\text { Film } \\
\text { Thickness } \\
\text { in } \mathrm{nm}\end{array}$ \\
\hline 500,000 & -10 to-100 & 5 & 22 \\
\hline 50,000 & & 7 & 25 \\
\hline 500 & \pm 50 & 12 & 40 \\
\hline 50 & & 12 & 67 \\
\hline 5 & +10 to +30 & 13 & 270 \\
\hline 0.5 & +50 to +100 & 16 & 2,500 \\
\hline & & & \\
\hline
\end{tabular}

FIGURE 3 Relationship between film thickness, composition and surface resistivity for electroless nickelphosphorus films

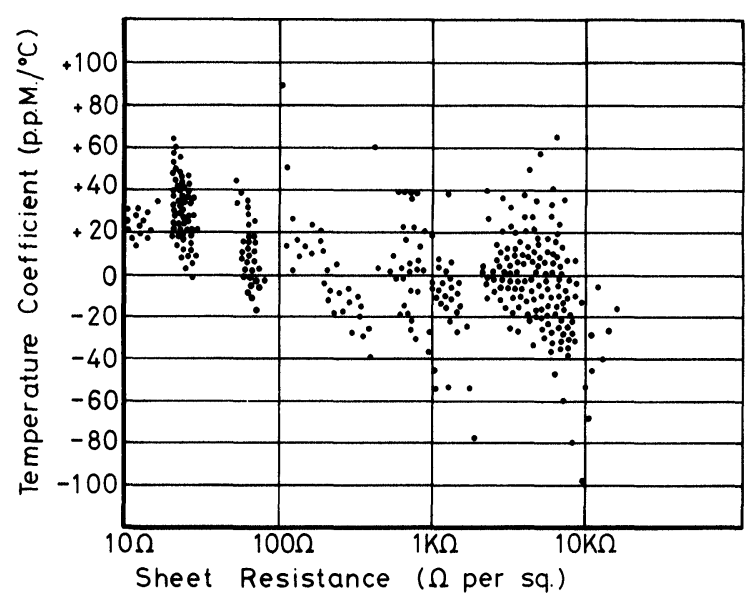

FIGURE 4 The temperature coefficient of typical batches of metal film resistors of various sheet resistivities

It is interesting to note that the metal film resistors marketed by other companies use evaporated nickel-chromium which in itself gives equally good resistor performance but produces only a narrow range of resistivities i.e. $10 \mathrm{ohm}$ per square to just over $1 \mathrm{kohm}$ per square.

The excellent electrical stability of the electroless nickel-phosphorus film is obtained by heating for several hours at an elevated temperature. This completes any Iatent chemical reactivity within the film and promotes the formation of the inert compound nickel phosphides.

In order to ensure freedom from attack by moisture the film is chemically treated to give it an outer passivated layer.

The number of resistor blanks or prevalues which can be produced per batch is limited only by the size of the vessels in which they are plated. It also follows that the maximum size of the resistor is dictated only by the size of the vessel.

Resistors are produced from a few millimetres in 


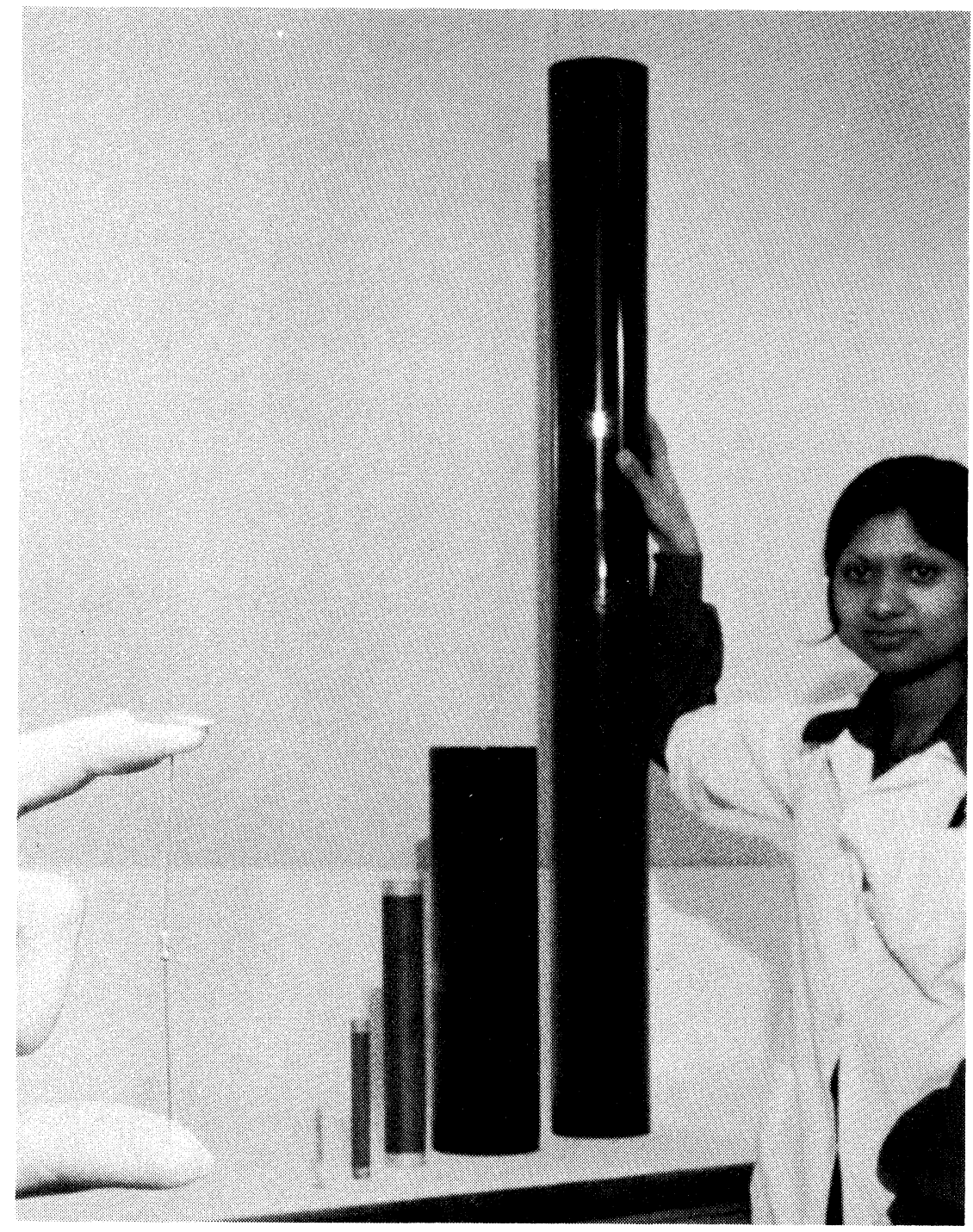

FIGURE 5 Electroless nickel-phosphorus metal film resistors

length to well over 1 metre. Examples are shown in Figure 5.

To give the resistors protection from mechanical damage and an extra barrier against hostile environments they are finally coated with an organic lacquer containing an epoxy resin. This also provides the necessary electrical insulation.

Since this process was introduced, very large numbers of high quality precision resistors have been sold to the U.K. and foreign markets and it is believed that it is the only commercial electroless process in the world producing metal film resistors in such large numbers over such a wide range of values and sizes.

\subsection{Integrated Circuits}

Shortly after the introduction of these metal film resistors it became evident that there was a lobby within the electronics industry which cast doubt on the reliability of circuits constructed from wire and discrete components, mainly due to failure at the soldered joints. 
The so-called integrated circuit was seen as an answer to these doubts. This concept involved the simultaneous deposition of resistors onto a flat ceramic substrate followed by conductors. This gave a continuous circuit intimately bonded over its entirety to the substrate.

Once again the use of electroless plating processes appeared to offer a simple and effective solution.

The process adopted was based essentially on a ceramic substrate although circuits were also produced in limited quantities on glass epoxy laminate. The build-up of the circuit on the substrate took the following route:-

The substrate was chemically cleaned, activated and coated all over with the electroless nickelphosphorus resistive layer. This layer was stabilised and passivated by subjecting it to the appropriate thermal and chemical treatments.

Using a screen printed lacquer mask or photo-resist technique, the resistive layer was fully protected except where the conductor limbs would be required - these parts were left exposed. The conductor limbs were reinforced with a heavy deposit of low resistivity, low phosphorus content, electroless nickel.

The lacquer mask was removed and by similar screen printing or photoresist techniques the conductor areas were protected and a mask formed of the resistor pattern. The exposed resistive nickel was etched away and the lacquer layer removed.

This produced the required reliable array of resistors and conductors, examples of which are shown

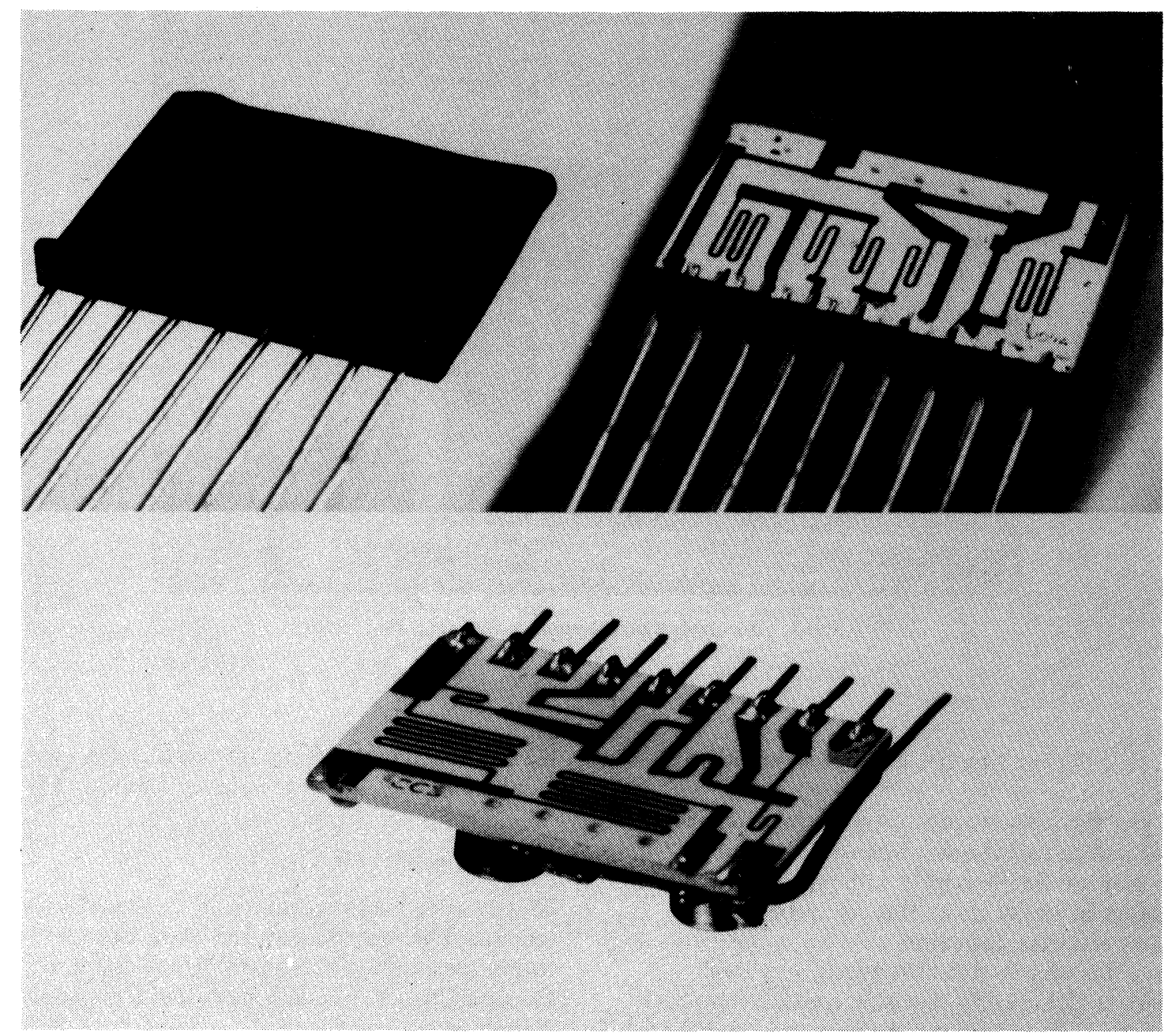

FIGURE 6 Electroless nickel-phosphorus metal film integrated circuits 
in Figure 6. The discrete components, i.e. capacitors and active devices, were soldered directly onto the appropriate termincal pads.

Terminal wires were securely attached through holes in the substrate and the unit was protected with lacquer and potted in a moulded plastic box using one of the many standard potting resins.

This thin film integrated circuit was in production from 1962 to 1970 and during this time about a quarter of a million modules were sold.

The process was eventually superseded by the screen printed thick film technique due mainly to the fact that it was a cheaper process and the properties of the thick film resistors were as good as, and in some respects, better than the thin film resistors.

\subsection{Temperature Sensors}

In studying the oxidation rates at elevated temperatures of electroless nickel, nickel-phosphorus and nickel-boron films, it became evident that the presence of the small amount of boron in the nickel boron system significantly retarded the oxidation rate.

It was also shown that the presence of the boron did not cause the T.C.R. to deviate from that of bulk nickel. This is illustrated in Figure 7 where it can be seen that the $\mathbf{R}-\mathrm{T}$ curve for the nickel-boron film is parallel to the nickel wire resistor. From these graphs the T.C.R. is $+4300 \mathrm{ppM} /{ }^{\circ} \mathrm{C}$ at $20^{\circ} \mathrm{C}$ falling to $+3800 \mathrm{ppM} /{ }^{\circ} \mathrm{C}$ at $300^{\circ} \mathrm{C}$ and is $+1150 \mathrm{ppM} /{ }^{\circ} \mathrm{C}$ at $500^{\circ} \mathrm{C}$.

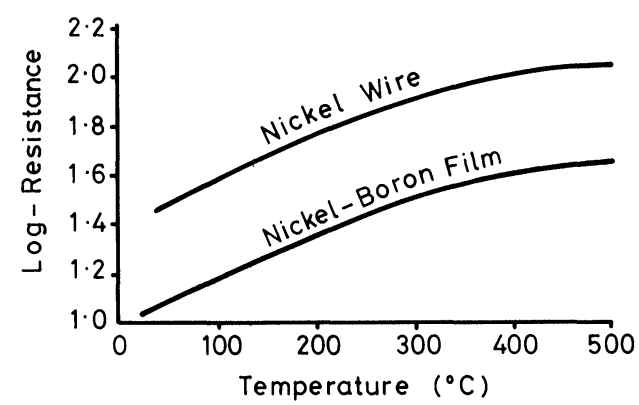

FIGURE 7 Variation of resistance with temperature of a nickel wire resistor and a nickel-boron film resistor

Temperature sensors made from nickel wire have an upper operating temperature of $200^{\circ} \mathrm{C}$ and in addition, they are relatively expensive to produce due to the problems of winding the thin wires to a precise resistance value.

The ability to produce a thermally stable film on a ceramic substrate with a T.C.R. equivalent to that of nickel opened up the possibility of producing a temperature sensor cheaper than the nickel wire sensor but with a superior thermal performance.

The nickel boron film was deposited onto an alumina rod using one of the many solution compositions suggested by Narcus. ${ }^{8}$ In this particular application the bath containing ethylene diamine as the complexing agent was preferred because of its superior chemical stability.

After deposition, the film was heat treated at temperatures in excess of $400^{\circ} \mathrm{C}$. This maximised crystallisation and grain growth and also gave the film its "nickel like" T.C.R.

The surface resistivity of the film after this heat treatment was of the order of $0.1 \mathrm{ohm}$ per square. Heat resistant nickel chrome caps were pressed onto the rod to provide electrical contact and its resistance value was raised to a useable level by cutting a helical groove in the film. There are no problems in producing values beyond $100 \mathrm{ohm}$ using high gain laser cutting techniques.

Heavy gauge nickel lead wires were welded onto the caps and a protective layer of an alkali-free inorganic cement was applied.

The change in resistance value with time at $500^{\circ} \mathrm{C}$ in air is shown in Figure 8.

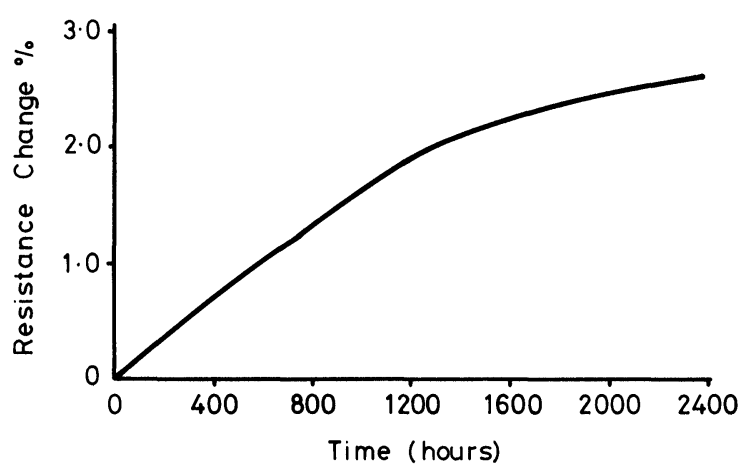

FIGURE 8 Change of resistance with time at $500^{\circ} \mathrm{C}$ for a nickel-boron film protected with an inorganic cement

It is clear from this information that this product fills a gap in the market place for a cheap temperature sensor with properties superior to nickel but admittedly not as good as the very expensive platinum wire sensor.

\subsection{Electrostatic Loudspeaker}

The electrostatic loudspeaker depends for its perfection of sound reproduction on many design 
features but one of these looms high on the list of requirements and that is the efficiency of coupling between the vibrating Mylar diaphragm and the surrounding air. This in turn demands a uniform electrostatic field across the electrode gap.

One way of achieving this uniformity was to apply a high surface resistivity layer uniformly over the entire surface of the diaphragm so that all incidental leakage paths were over-ridden by this lower resistivity "spreader".

An adequate level of surface resistivity was stated to be within $10^{8}$ and $10^{10} \mathrm{ohm}$ per square but in producing this film it was made clear that the added weight to the diaphragm must be minimal because of its possible damping effect on the diaphragm vibration. At this time problems were being experienced using a conductor loaded resin layer where the value was achievable but the weight was too high.

The obvious answer was to apply a very thin, almost weightless layer, of a metal conductor. The diaphragms were, however, far too big ( $2 \mathrm{ft}$. long $x$ 7 in wide) to be accommodated in a vacuum bell jar such that a uniform film could be evaporated or sputtered over the entire surface.

Electrolessly deposited films did look as though they could be the answer to the uniformity requirement because the diaphragm could be formed into the base of the metallising vessel by sticking a plastic wall around the edge of the diaphragm frame and plating over the whole surface of the diaphragm.

Conventional activation, followed by short exposures to nickel-phosphorus plating solutions produced the required average resistivity but did not give a sufficient degree of uniformity and so this approach had to be abandoned.

However, during the course of this work it was noted that under certain conditions of activation the colourless Mylar diaphragms assumed a very uniform brown colouration which, when dried out, had a resistivity in the required range of $10^{8}$ to $10^{10} \mathrm{ohm}$ per square and which showed little or no variation over the entire surface of the diaphragm.

A study was made of the factors which favoured the deposition of the film and the variants which dictated the ultimate value of the resistivity.

Using separate treatments firstly of stannous chloride solution and then palladium chloride solution gave no measureable film deposition. However, the use of an acidic colloidal suspension of palladium ${ }^{13}$ prepared by using an admixture of palladium and stannous chlorides in a strong solution of hydrochloric acid produced the desired film with the

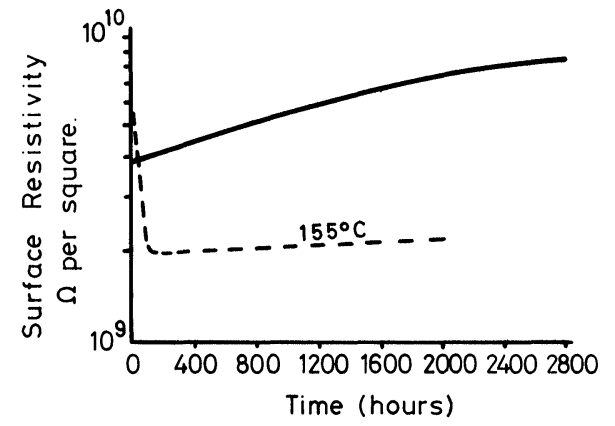

FIGURE 9 Change in resistance with time for a palladiumtin film on Mylar at room temperature and $155^{\circ} \mathrm{C}$.

preferred resistivity. The film was shown to be a mixture of elemental palladium and stannic acid.

It was shown that the surface resistivity achieved was independent of the contact time providing it was beyond one minute and was also independent of temperature within the range $25^{\circ} \mathrm{C}$ to $80^{\circ} \mathrm{C}$. It was, however, dependent on the ratio of stannous chloride to palladium chloride and by controlling this a predetermined surface resistivity could be obtained.

The film was about $10 \mathrm{~nm}$ thick and therefore came well within the maximum weight requirement. It was also shown that even in its unprotected state the surface resistivity stayed well within its decade value when stored at room temperature for up to 3000 hours. Even when exposed to a $155^{\circ} \mathrm{C}$ ambient the electrical stability was virtually unaltered (see Figure 9).

\section{CONCLUSIONS}

From the work reported in this paper it can be seen that there is no doubt about the usefulness of electrolessly deposited "metal" films in the field of electronics. Only electroless plating appropriate to resistor technology has been dealt with but it is clear that the properties and processes can be manipulated over a wide spectrum to satisfy a multitude of requirements and will without doubt continue to provide solutions to many other problems where thin film technology is dominant.

\section{REFERENCES}

1. Wein, Metal Finishing, November \& December 1964.

2. Wein, Metal Finishing, January 1945.

3. Wurtz, Comptes Rendres de l'Academie des Sciences Vol. 18, April 1844, p. 702; Vol. 21, p. 149, 1865. 
4. A. Brenner and G. E. Riddell, Journal of Research, Nat. Bureau of Standards Vol. 39, Nov. 1947, p. 385-395.

5. A. Brenner, Metal Finishing, December 1954, p. 61.

6. G. Gutzeit, A.S.T.M. Special Technical Publication, No. 265. Nov. 1959 , p. 3-12.

7. J. W. Dini and P. R. Coronado, Plating, April 1967, p. $385-390$.

8. H. Narcus, Plating, April 1967, p. 380-381.

9. British Patent 885, 239.
10. J. Dearden, Electronic Components 1968, Feb. p. 178-182.

11. British Patent 1, 119, 741.

12. P. L. Kirby, Electronic Components 1965 , June p. 521-526.

13. British Patent, $1,347,549$.

14. W. Goldie, Metallic Coating of Plastics, Volume I: Electrochemical Publications Ltd. 

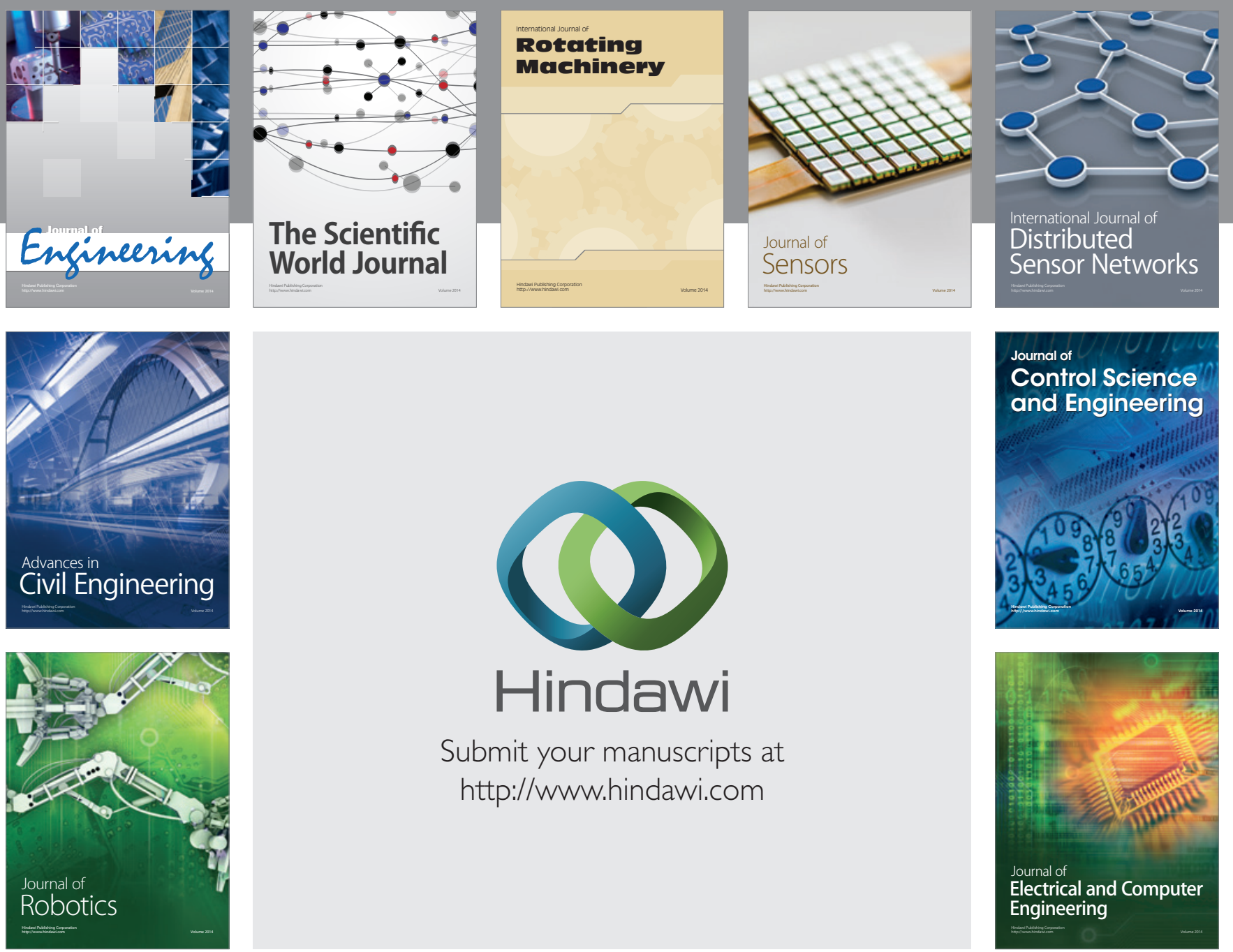

Submit your manuscripts at

http://www.hindawi.com
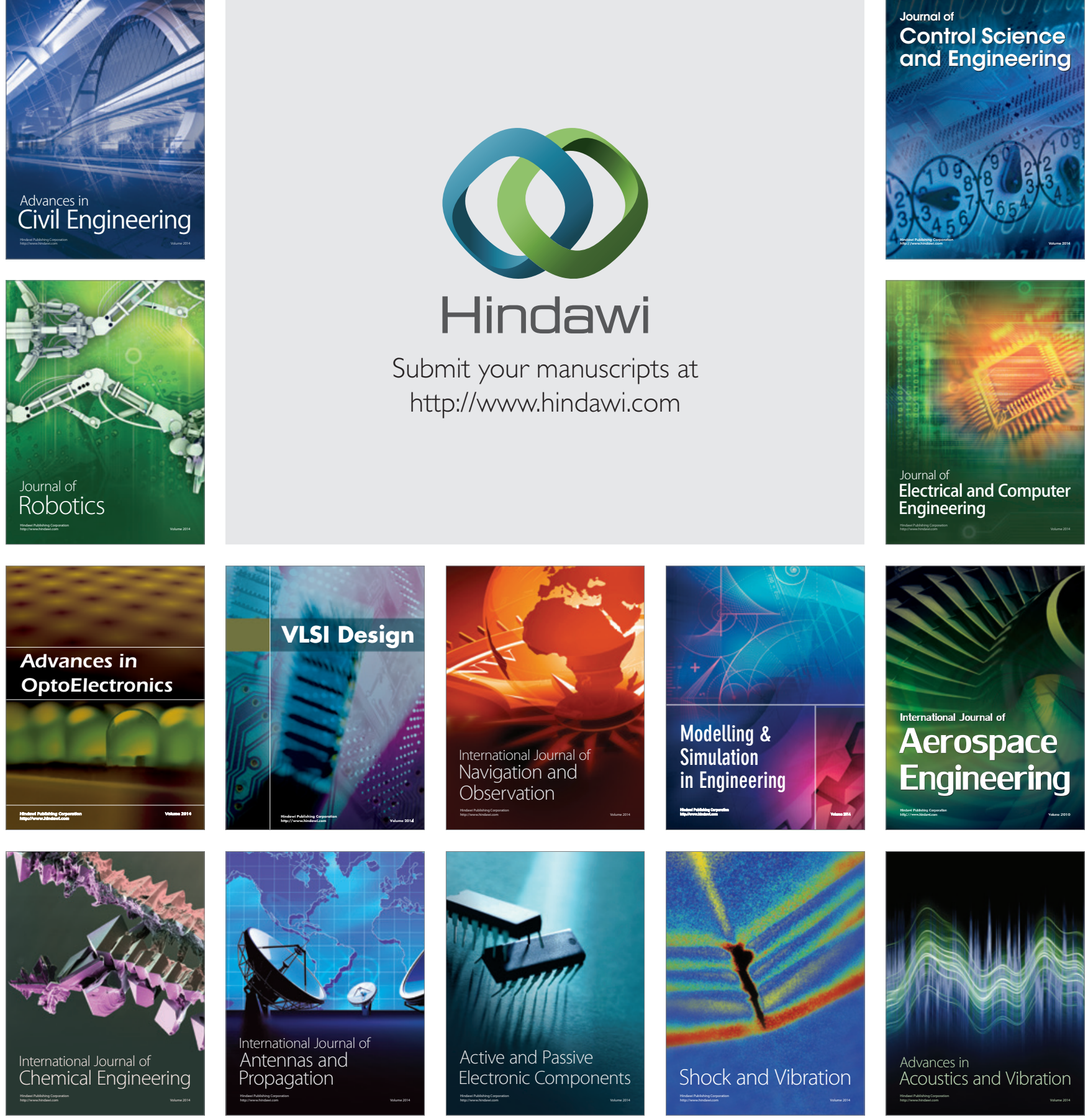